\title{
Formulasi Dan Evaluasi Sifat Fisik Tablet Hisap Kombinasi Ekstrak Daun Bakau Hitam (Rhizophora Mucronata) Dan Vitamin C Sebagai Antioksidan
}

\author{
Ade Dwi Marwati ${ }^{1}$, Asep Nurrahman Yulianto ${ }^{2 *}$, Lulu Setiyabudi ${ }^{3}$ \\ ${ }^{1,2,3}$ Studi Farmasi STIKES Al-Irsyad Al-Islamiyyah Cilacap, Jawa Tengah, Indonesia \\ Email correspondence : *nurrahmanasep@yahoo.co.id
}

\begin{abstract}
ABSTRAK
Daun bakau hitam Rhizophora mucronata merupakan salah satu tanaman bakau yang berpotensi sebagai sumber antioksidan alami. Vitamin $C$ merupakan antioksidan kuat yang mengikat dan menghilangkan radikal bebas berbahaya dari tubuh. Penelitian ini bertujuan untuk mengetahui formulasi, evaluasi sediaan dan efektivitas antioksidan tablet hisap dari kombinasi ekstrak daun bakau hitam (Rhizophora mucronata) dan vitamin C dengan metode granulasi basah yang tepat. Formulasi tablet hisap dibuat dengan variasi konsentrasi PVP 3\% (F1), 4\% (F2), dan 5\% (F3). Kombinasi ekstrak daun bakau hitam dan vitamin $C$ dalam perbandingan 1:6. Evaluasi sediaan tablet hisap meliputi uji organoleptis, uji keseragaman bobot, uji kerapuhan yang dianalisis secara deskriptif dan uji waktu alir, sudut diam dan uji kekerasan tablet yang di analisis menggunakan one way ANOVA. Aktivitas antioksidan diuji menggunakan metode DPPH (1,1-Diphenyl-2-Picrylhidrazil). Hasil penelitian menunjukkan bahwa F3 adalah formula terbaik dengan hasil waktu alir granul 6,14 detik, sudut diam 27,31 , indexs pemampatan 0,88\% dan tingkat kekerasan tablet rata-rata $12,7 \mathrm{~kg} / \mathrm{cm}^{2}$, kerapuhan 0,8\%, waktu hancur 13 menit 22 detik, waktu larut 9 menit 32 detik, dan nilai IC 50 sebesar 125,27 $\mu \mathrm{g} / \mathrm{mL}$ yang termasuk antioksidan sedang. Data one way ANOVA variasi pvp berpengaruh signifikan terhadap kekerasan tablet dan tidak berpengaruh terhadap waktu alir dan sudut diam granul.
\end{abstract}

Kata kunci : Tablet Hisap, Daun Bakau Hitam, Antioksidan, PVP

\begin{abstract}
Black mangrove leaves Rhizophora mucronata is one of the mangrove plants which is a source of natural antioxidants. Vitamin $C$ is a powerful antioxidant that binds and removes harmful free radicals from the body. This study aims to determine the formulation, evaluation of preparations and suction antioxidant tablets from a combination of black mangrove leaf extract (Rhizophora mucronata) and vitamin $C$ with the right wet granulation method. Suction tablet formulations were made with variations in the concentration of PVP 3\% (F1), 4\% (F2), and 5\% (F3). Combination of black mangrove leaf extract and vitamin $C$ in a ratio of 1: 6 . Evaluation of tablet preparations using organoleptic test, weight uniformity test, fragility test analyzed descriptively and flow time test, the degree of granul and tablet test were analyzed using one way ANOVA. The antioxidant activity cites using the DPPH method (1,1-Diphenyl-2Picrylhidrazil). The results showed that $F 3$ is the best formula with a granular flow time of 6.14, the degree of granul $27.31^{\circ}$, a compression index of $0.88 \%$ and a tablet of an average hardness of $12.7 \mathrm{~kg} / \mathrm{cm} 2$, a fragility of $0.8 \%$, a time of 13 minutes 22 seconds, dissolution time 9 minutes 32 seconds, and IC50 values of $125.27 \mu \mathrm{g} / \mathrm{mL}$ which are included as moderate antioxidants. The one way ANOVA data variation pvp has a significant effect on resistance tablets and disagrees with the flow time and granular standpoint.
\end{abstract} Keywords: Lozenges, Black Mangrove Leaves, Antioxidants, PVP

\section{PENDAHULUAN}

Antioksidan adalah senyawa atau zat yang dapat menghambat, menunda, mencegah atau memperlambat reaksi oksidasi meskipun dalam kosentrasi yang kecil. Oksidasi adalah reaksi 
kimia yang dapat menghasilkan radikal bebas sehingga memicu reaksi berantai (chain reaction)[1].

Salah satu tanaman yang mengandung antioksidan adalah daun bakau hitam. Daun bakau hitam memiliki potensi kandungan bioaktif yang sangat tinggi, kandungan dari tumbuhan ini salah satunya dapat digunakan sebagai antioksidan[2]. Daun bakau hitam Rhizophora mucronata merupakan salah satu sumber antioksidan alami. Metabolit sekunder flavonoid yang terkandung dalam daun bakau Rhizophora mucronata mengandung antioksidan, yang mana aktivitas radikal bebas dapat diredam dengan pemberian antioksidan[1]. Penurunan Vitamin C mempunyai peran penting terhadap tubuh manusia, karena dalam vitamin $\mathrm{C}$ memiliki aktivitas antioksidan. Dalam sebuah penelitian vitamin $\mathrm{C}$ mampu mendonorkan atom hidrogen ke radikal bebas DPPH membentuk senyawa DPPH tereduksi yang stabil. Semakin tinggi kandungan vitamin C maka semakin banyak radikal DPPH yang bereaksi sehingga konsentrasi semakin berkurang [3].

Tablet hisap adalah salah satu pengembangan yang dapat dilakukan karena lebih praktis dan mudah dalam penggunaan maupun penyimpanannya[4]. Parameter yang perlu diperhatikan pada formulasi tablet hisap selain dosis adalah rasa, yang merupakan sifat untuk dapat diterima di masyarakat. Sedangkan untuk menutupi rasa pahit dari ekstrak daun bakau hitam pada tablet hisap digunakan manitol sebagai pemanis agar dapat diterima oleh konsumen.

\section{METODE PENELITIAN}

Metode yang digunakan dalam penelitian ini adalah metode eksperimental. Dimana penelitian ini dilakukan di Laboratorium Teknologi Sediaan Farmasi dan Laboratorium Kimia, STIKES Al-Irsyad Al-Islamiyyah Cilacap pada bulan Maret 2020. Pengumpulan data dilakukan dengan cara ceklis dengan buku yang disiapkan untuk penelitian dan pelaksanaan penelitian dicatat dibuku logbook. Data yang digunakan adalah data hasil uji granul dan uji tablet. Uji granul diantaranya uji waktu alir, sudut diam dan uji pemampatan. Sedangkan, uji sifat fisik tablet meliputi uji organoleptik, uji keseragaman bobot, uji kekerasan, uji kerapuhan, uji waktu hancur, dan uji waktu larut. Hasil uji organoleptik, uji keseragaman bobot, uji kerapuhan, uji waktu hancur dan uji waktu larut dianalisis secara deskriptif sedangkan hasil uji waktu alir granul, uji sudut diam, dan uji kekerasan tablet dianalisis dengan oneway ANOVA untuk membandingkan ada tidaknya perbedaan yang signifikan antar formulasi.

\section{HASIL DAN PEMBAHASAN}

\section{Ekstraksi Daun Bakau Hitam}

Ekstrak diperoleh dengan cara maserasi selama 3 x 24 jam dengan pelarut etanol $96 \%$. Maserasi simplisia daun bakau hitam diperoleh ekstrak sebanyak 127,67gram dengan hasil rendemen yang didapatkan yaitu $25,53 \%$.

2. Uji Kadar Air dalam Ekstrak Daun Bakau Hitam

Hasil yang diperoleh dari uji kadar air ekstrak etanol $96 \%$ daun bakau hitam yaitu sebesar $8 \%$. Dengan range yaitu ekstrak kering air $<5 \%$, ekstrak kental 5-10\%, ekstrak cair $>20 \%$.

\section{Skrining Fitokimia}

Berdasarkan analisis yang dilakukan, diketahui bahwa didalam daun bakau hitam positif mengandung senyawa flavonoid, tanin, dan saponin.

\section{a. Flavonoid}

Senyawa flavonoid dibuktikan terbentuk sedikit busa dengan perubahan warna menjadi jingga setelah ditambahkan serbuk $\mathrm{Mg}$ dan $\mathrm{HCl}$ pekat. Dalam ekstrak tumbuhan dapat diketahui apabila terdapat senyawa flavonoid saat penambahan $\mathrm{Mg}$ dan $\mathrm{HCl}$ akan terbentuk garam flavilium, garam ini lah yang dapat memberikan warna merah atau jingga[5].Reaksi kimia yang terjadi digambarkan seperti Gambar 1 


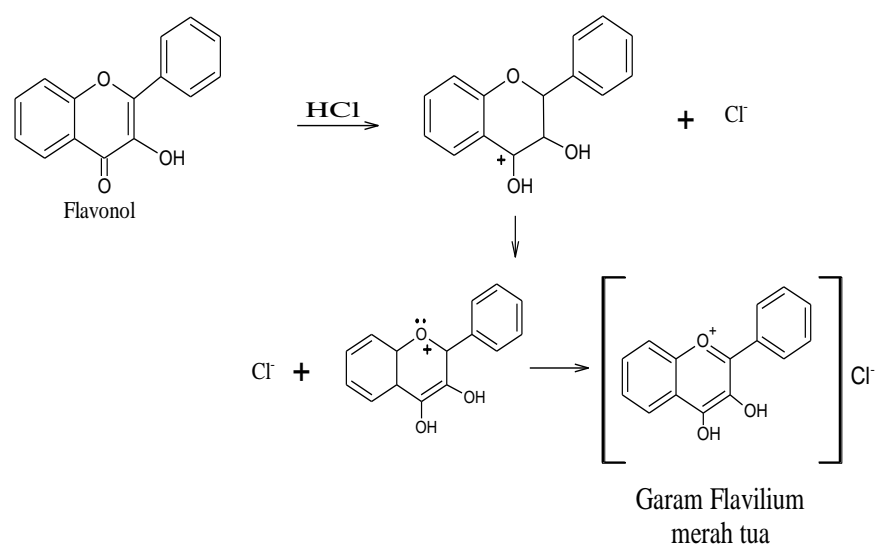

Gambar 1. Mekanisme Reaksi Pembentukan Garam Flavilium

b. Tanin

Uji tanin dibuktikan dengan menghasilkan suatu warna hijau kecoklatan, karena reaksi antara tanin dan $\mathrm{FeCl} 3$ membentuk senyawa kompleks. Terbentuknya senyawa kompleks antara tanin dan $\mathrm{FeCl} 3$ karena adanya ion $\mathrm{Fe} 3+$ sebagai atom pusat dan tanin memiliki atom $\mathrm{O}$ yang mempunyai pasangan elektron bebas yang bisa mengkoordinasikan ke atom pusat sebagai ligannya[6]. Reaksi kimia yang terjadi digambarkan seperti Gambar 2<smiles>Oc1ccc2c(c1)OC(c1ccc(O)c(O)c1)C(O)C2</smiles>

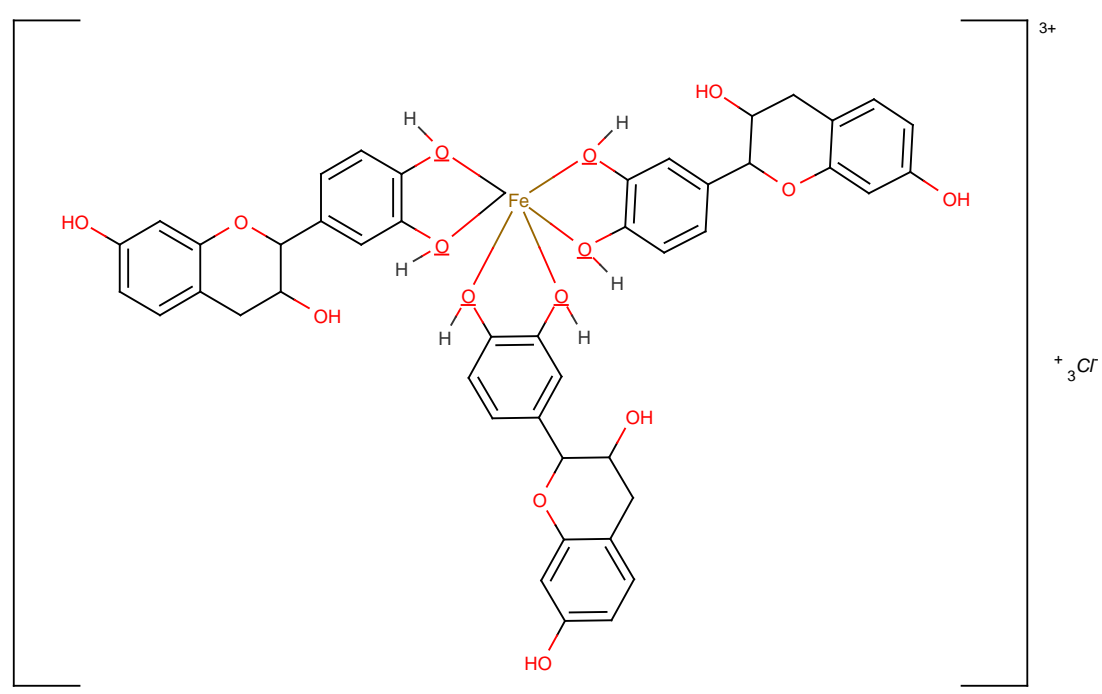

\section{Gambar 2. Reaksi antara Tanin dan $\mathrm{FeCl}_{3}$.}

\section{c. Saponin}

Uji saponin dibuktikan dengan terbentuknya busa permanen dan tidak hilang pada penambahan $2 \mathrm{~mL} \mathrm{HCl} 0.1 \mathrm{~N}$. Timbulnya buih menunjukkan adanya glikosida yang 
terhidrolisis menjadi glukosa dan senyawa lainnya. Reaksi kimia yang terjadi digambarkan seperti Gambar 3

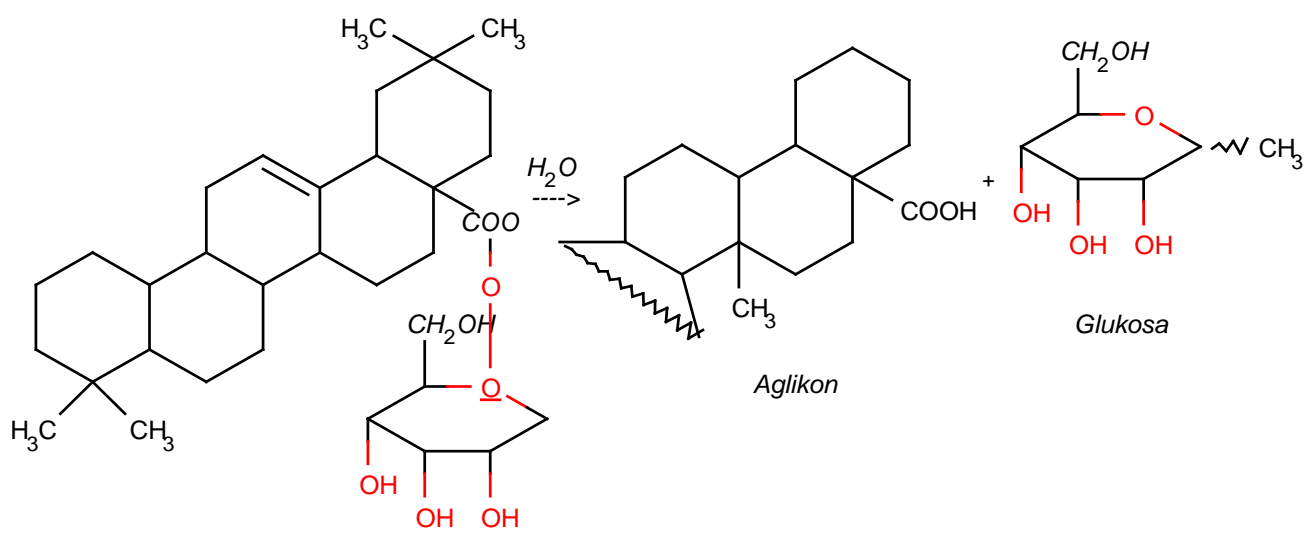

I-Arabinopiriosil- ${ }_{3} \beta$-asetil oleanolat

Gambar 3. Reaksi Saponin dengan Aquadest

\section{Evaluasi Sifat Fisik Granul}

a. Uji Waktu Alir

Uji waktu alir granul menunjukkan bahwa setiap formulasi granul waktu alirnya kurang dari 10 detik untuk 10gram serbuk granul, bahwa waktu alir F3 lebih cepat dari pada F1 dan F2, karena F3 mengandung bahan pengikat PVP lebih banyak. Pengujian ini menunjukkan bahwa semua formulasi memenuhi persyaratan waktu alir. Semakin cepat waktu alir granul menandakan semakin baiknya sifat alir granul tersebut yang akan berpengaruh pada keseragaman bobot dan ukuran tablet[7].

\section{b. Uji Sudut Diam}

Uji sudut diam menunjukkan bahwa pemeriksaan sudut diam granul dari ketiga formula memenuhi syarat yaitu $<40^{\circ}$, menunjukkan bahwa granul dapat mengalir bebas. Semakin kecil sudut diam maka alir granul akan semakin baik.

\section{c. Uji Pemampatan}

Uji pemampatan granul menunjukkan hasil dari ketiga formula memenuhi syarat yaitu $<20 \%$. Serbuk memiliki sifat alir yang baik jika indeks pemampatannya kurang dari 20\% [8]

\section{Evaluasi Sifat Fisik Tablet Hisap}

\section{a. Uji Organoleptis}

Uji organoleptis meliputi pemeriksaan bentuk, warna, bau, dan rasa dari sediaan, dari ketiga formulasi menunjukkan bahwa formulasi menghasilkan bentuk, bau, dan rasa yang sama yaitu tablet berbentuk bulat pipih, berbau khas ekstrak dan rasa manis. Sedangkan ketiga formula memiliki warna yang berbeda yaitu pada F1 terjadi mottling atau distribusi warna tablet tidak merata yaitu berwarna coklat berbintik.

\section{b. Uji Keseragaman Bobot}

Berdasarkan Farmakope Indonesia edisi IV tidak lebih dari dua tablet yang mempunyai penyimpangan bobot lebih dari 5\% dan tidak boleh dari satu tablet pun yang mempunyai penyimpangan lebih dari 10\%. Pada ketiga Formulasi F1, F2 dan F3 memenuhi persyaratan CV yang diperoleh kurang dari $5 \%[9]$. 


\section{c. Uji Kekerasan}

Uji kekerasan tablet hisap menunjukkan dari ketiga formulasi memenuhi standar kekerasan tablet. menunjukkan bahwa tablet hisap memenuhi syarat untuk tablet hisap yaitu kekerasannya antara $10-20 \mathrm{~kg} / \mathrm{cm}^{2}[10]$.

d. Uji Kerapuhan

Uji kerapuhan tablet hisap menunjukkan bahwa ketiga formula memenuhi syarat kerapuhan tablet hisap yaitu kerapuhan kurang dari $1 \%$. Nilai kerapuhan yang lebih besar dari 1\% dianggap kurang baik [11].

\section{e. Uji Waktu Hancur}

Uji waktu hancur tablet dari ketiga formula menunjukkan bahwa pengujian waktu hancur (desintegrasi) menunjukkan 6 tablet hisap ekstrak daun bakau hitam dan vitamin C untuk F1 hancur pada menit ke 9,46 detik, F2 11,39 dan F3 13,22. Tablet hisap memenuhi syarat waktu hancur, karena kurang dari 15 menit.

\section{f. Uji Waktu Larut}

Uji waktu larut tablet ketiga formula menunjukkan bahwa waktu larut untuk ketiga formula tablet hisap yang dibuat memenuhi persyaratan yaitu berdasarkan teori tablet hisap melarut dalam waktu $5-10$ menit.

\section{Pengujian Aktivitas Antioksidan Sediaan Tablet Hisap Ekstrak Daun Bakau Hitam Rhizophora mucronata dan Vitamin C dengan Metode DPPH}

Penentuan $\mathrm{IC}_{50}$ tablet hisap ekstak daun bakau hitam Rhizophora mucronata dan vitamin C dilakukan dengan metode peredaman DPPH sesuai prinsip dan prosedur yang dipaparkan oleh Molyneux (2004), yaitu adanya radikal bebas stabil DPPH yang dicampurkan dengan senyawa antioksidan yang memiliki kemampuan mendonorkan hidrogen, sehingga radikal bebas dapat diredam. Dimana pengukuran absorbansi sampel pada spektrofotometer dengan panjang gelombang $517 \mathrm{~nm}$. Dimana variasi konsentrasi sampel yang digunakan adalah 50, 100, 150, dan 200 ppm, sedangkan variasi konsentrasi pembanding adalah 5, 10, 15, dan $20 \mathrm{ppm}$. Pembanding yang digunakan sebagai kontrol positif adalah vitamin C. Menurut Molyneux (2004), menyatakan bahwa suatu zat mempunyai antioksidan sangat kuat apabila nilai $\mathrm{IC}_{50}<50 \mu \mathrm{g} / \mathrm{mL}$, kuat apabila nilai $\mathrm{IC}_{50}$ antara $50-100 \mu \mathrm{g} / \mathrm{mL}$, sedang apabila nilai $\mathrm{IC}_{50}$ berkisar antara $100-150 \mu \mathrm{g} / \mathrm{mL}$, lemah apabila nilai $\mathrm{IC}_{50}$ berkisar antara $150-200 \mu \mathrm{g} / \mathrm{mL}$ dan tidak aktif apabila $\mathrm{IC}_{50}$ diatas $250 \mu \mathrm{g} / \mathrm{mL}$.

Tabel 2. Hasil Uji Antioksidan

\begin{tabular}{llll}
\hline Sampel & Konsentrasi (ppm) & \% Inhibisi & IC $_{\mathbf{5 0}}(\mu \mathrm{g} / \mathrm{mL})$ \\
\hline Ekstrak Daun Bakau & 50 & 14,47 & \\
Hitam & & & \\
& 100 & 54,86 & \\
& 150 & 74,90 & 109,35 \\
& 200 & 84,60 & \\
Vit C Murni & Blanko & & \\
(Pembanding) & 5 & 34,32 & \\
& 10 & & \\
& 15 & 71,60 & \\
& 20 & 84,85 & 6,99 \\
& Blanko & 93,80 & \\
& & &
\end{tabular}




\begin{tabular}{llll}
$\begin{array}{l}\text { Tablet Hisap Ekstrak } \\
\text { Daun Bakau Hitam } \\
\text { dan vitamin C }\end{array}$ & 50 & 22,75 & \\
& 100 & & \\
& 150 & 37,5 & \\
& 200 & 59,19 & 125,27 \\
& Blanko & 80,17 & \\
$\begin{array}{l}\text { Tablet vitamin C } \\
\text { (Pembanding) }\end{array}$ & 50 & 46,13 & \\
& 100 & & \\
& 150 & 72,03 & \\
& 200 & 84,93 & 41,12 \\
& Blanko & 86,18 & \\
\hline
\end{tabular}

\section{KESIMPULAN}

Dari hasil penelitian sediaan tablet hisap dari ekstrak daun bakau hitam Rhizophora mucronata dengan vitamin $\mathrm{C}$ dapat disimpulkan bahwa formulasi terbaik tablet hisap ekstrak daun bakau hitam Rhizophora mucronata dan vitamin C adalah formula 3 yang mengandung PVP dengan konsentrasi 5\%. PVP dalam tablet hisap dapat meningkatkan waktu larut tablet, memperkecil tingkat kerapuhan tablet, dan mempengaruhi keseragaman bobot tablet, dengan hasil pada F1 waktu larut 6 menit 46 detik, kerapuhan tablet 0,9\%, keseragaman bobot CV 1,5\% $(<5 \%)$. Pada F2 hasil waktu larut 8 menit 51 detik, kerapuhan tablet $0,9 \%$, keseragaman bobot CV 1\% (<5\%). Pada F3 hasil waktu larut 9 menit 32 detik, kerapuhan tablet 0,8\%, keseragaman bobot CV 2,6\% (<5\%). Tablet hisap kombinasi daun bakau hitam Rhizophora mucronata dan vitamin $\mathrm{C}$ terbukti efektiv sebagai antioksidan yang mampu menangkal radikal bebas dengan nilai $\mathrm{IC}_{50}$ sebesar $125,27 \mu \mathrm{g} / \mathrm{mL}$ merupakan antioksidan sedang.

\section{DAFTAR PUSTAKA}

[1] A. Ridlo, R. Pramesti, K. Koesoemadji, E. Supriyantini, and N. Soenardjo, "Aktivitas Antioksidan Ekstrak Daun Mangrove Rhizopora mucronata," Bul. OSEANOGRAFI Mar., 2017, doi: 10.14710/buloma.v6i2.16555.

[2] A. A. Mohamed Hatha and J. Chacko, "World Atlas of Mangroves," Int. J. Environ. Stud., 2012, doi: 10.1080/00207233.2012.671593.

[3] A. Adawiah, D. Sukandar, and A. Muawanah, "Aktivitas Antioksidan dan Kandungan Komponen Bioaktif Sari Buah Namnam,” J. Kim. Val., 2015, doi: 10.15408/jkv.v0i0.3155.

[4] H. Nurcahyo, P. Purgiyanti, and H. Purwantiningrum, "Tablet Hisap Ektrak Daun Kemangi (Ocimum sanctum L) Dengan Menggunakan Pati Ganyong Sebagai Bahan Pengikat," Para Pemikir, vol. 1, no. 2, 2012, doi: http://dx.doi.org/10.30591/pjif.v1i2.147.g148.

[5] B. Meurer-Grimes and T. Robinson, "The Organic Constituents of Higher Plants.," Brittonia, 1992, doi: 10.2307/2807201.

[6] A. Kristianto et al., "Pengaruh Ekstrak Kasar Tanin Dari Daun Belimbing Wuluh ( Averrhoa Bilimbi L .) Pada Pengolahan Air ( the Effect of Crude Extract Tannins From Star Fruit' S Leaves ( Averrhoa Bilimbi L .) on Water Treatment," J. Berk. Sainstek, vol. 2, no. 1, pp. 54-58, 2014, [Online]. Available: http://jurnal.unej.ac.id/index.php/BST/article/view/1623.

[7] J. . Siregar Charles, "Farmasi Rumah Sakit : Teori dan Penerpan," in Buku Kedokteran $E G C, 2004$.

[8] A. R. Fassihi and I. Kanfer, "Effect of compressibility and powder flow properties on tablet weight variation," Drug Dev. Ind. Pharm., 1986, doi: 10.3109/03639048609042619. 
[9] L. H. Kurniati, T. S. Sulaiman, and W. Wahyono, "FORMULA OPTIMATION OF SENGGUGU ROOT BARK EXTRACT LOZENGES (Clerodendrum serratum (L.) Moon.) AS MUCOLYTIC AGENT WITH LACTOSE - SORBITOL FILLER COMBINATION," Maj. Obat Tradis., vol. 20, no. 2, pp. 68-80, 2015, doi: 10.22146/tradmedj.8075.

[10] R. Tierney, W. Hermina, and S. Walsh, "The pharmaceutical technology landscape: A new form of technology roadmapping," Technol. Forecast. Soc. Change, vol. 80, no. 2, pp. 194-211, 2013, doi: 10.1016/j.techfore.2012.05.002.

[11] L. Lachman, “Teori dan Praktek Farmasi Industri,” Ed. Ketiga, 1994. 